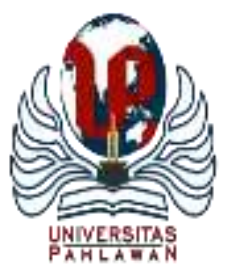

\title{
JURNALBASICEDU
}

Volume 5 Nomor 6 Tahun 2021 Halaman 5035-5042

Research \& Learningin Elementary Education https://jbasic.org/index.php/basicedu

\section{Pengembangan Modul Pembelajaran terhadap Hasil Belajar Mata Pelajaran Aqidah di SekolahDasar}

\author{
Jumiati Siska $^{1 凶}$, Muhammad Kristiawan ${ }^{2}$
}

Pendidikan Komputer, Universitas Dehasen Bengkulu, Universitas Bengkulu ${ }^{1,2}$

E-mail: Jesiskaalghazali@gmail.com ${ }^{1}, \underline{\text { muhammadkristiawan@ @unib.ac.id }}^{2}$

\begin{abstract}
Abstrak
Modul belajar berformat komik sebagai media pembelajaran memiliki pengaruh yang sifatnya membangun pemahaman siswa untuk menghayati dan mengamalkan ajaran Islam, yang akan menjadi landasan ibadah dalam kehidupannya. Tujuan dari penelitian ini adalah untuk mengembangkan buku teks fikih berformat komik untuk sekolah dasar Islam. Metode penelitian menggunakan model Research and Development. Populasi dan sampel yang terlibat dalam penelitian ini adalah siswa kelas 1 SD Islam Rabbanni. Hasil kajian pengembangan buku teks aqidah berformat komik ini valid, berdasarkan validasi ahli isi $95 \%$, validasi ahli desain $92,7 \%$, hasil uji coba individu $100 \%$, hasil uji coba kelompok kecil 95\%, dan hasil uji coba kelompok besar mencapai $97,82 \%$. Hasil analisis uji t dengan taraf signifikansi 0.05 menunjukkan bahwa $\mathrm{p}$ value $\mathrm{t}$ test adalah 0,00 yang berarti $(<0,05)$. Hal ini menunjukkan bahwa buku teks fikih berformat komik dapat berpengaruh signifikan dan efektif meningkatkan hasil belajar siswa SD Islam
\end{abstract}

Kata Kunci: inovasi buku ajar fiqih, komik, siswa SD 1.

\begin{abstract}
The comic-format learning module as a learning medium has an influence that builds students' understanding to appreciate and practice Islamic teachings, which will become the foundation of worship in their lives. The purpose of this research is to develop fiqh textbooks in comic format for Islamic elementary schools. The research method uses the Research and Development model. The population and samples involved in this study were grade 1 students of SD Islam Rabbanni. The results of the study on the development of the aqidah text book in comic format are valid, based on 95\% content expert validation, 92.7\% design expert validation, 100\% individual trial results, 95\% small group trial results, and large group trial results reaching 97, 82\%. . The results of the t-test analysis with a significance level of 0.05 showed that the p-value of the $t$-test was 0.00 , which means $(<0.05)$. This shows that fiqh textbooks in comic format can have a significant and effective effect on improving the learning outcomes of Islamic elementary school students
\end{abstract}

Keywords: innovation of fiqh textbooks, comics, elementary school students 1.

Copyright (c) 2021 Jumiati Siska, Muhammad Kristiawan

$\triangle$ Corresponding author :

Email : Jesiskaalghazali@gmail.com

DOI : https://doi.org/10.31004/basicedu.v5i6.1570 


\section{PENDAHULUAN}

Salah satu pendukung dalam proses pembelajaran adalah penggunaan bahan ajar seperti buku teks yang memiliki ilmu pengetahuan, disusun mengikuti kurikulum yang digunakan oleh guru dan siswa disekolah (Rahmadi, 2019). Berbagai macam ilmu tercakup dalam buku teks, salah satunya adalah ilmu Fiqih. Ketika membaca buku-buku fikih tersebut, siswa akan didorong untuk berpikir dan melakukan hal-hal yang positif, misalnya dengan melakukan pengamatan yang disarankan dalam buku teks kemudian mengadakan pelatihanpelatihan yang diinstruksikan di dalamnya agar siswa dapat memecahkan masalah yang disajikan di dalamnya (Nita Nur Qoriah, 2017). Dengan dorongan yang membangun atau motif yang buruk akan terhambat dan berkurang (Heglund, 2016). Oleh karena itu, bagi siswa, buku teks akan mempengaruhi kepribadian mereka, meskipun pengaruhnya tidak sama antara siswa satu dengan yang lainnya.

Jika dilihat dari tujuan dan kegunaan buku ajar, salah satunya adalah untuk memudahkan pendidik dalam menyampaikan materi pembelajaran kepada siswa (Restian \& Sari, 2019). Proses-proses tersebut dapat disebut proses komunikasi (Lestari, Wulansari, \& Khasanah, 2021). Komunikasi adalah pengiriman pesan dari sumber pesan melalui saluran atau media tertentu kepada siswa sebagai penerima pesan (Heglund, 2016). Bentuk komunikasi berlaku di semua keadaan hubungan sosial, termasuk pembelajaran (Rofifah, 2020). Hubungan komunikasi pembelajaran berlangsung, yaitu interaksi edukatif antara pendidik dan peserta didik. Agar maksud dan tujuan komunikasi dapat berjalan dengan baik dan mendapatkan hasil yang maksimal maka diperlukan sarana dan prasarana. Salah satu sarana dan prasarana tersebut adalah buku ajar Aqidah model komik anak (Hosler \& Boomer, 2020). Jadi siswa SD Islam, kesenangan terhadap komik dapat dijadikan indikator pemilihan objek untuk pengembangan media pembelajaran. Komik yang jauh dari edukatif dapat diubah menjadi lebih edukatif dan bermanfaat untuk pembelajaran (Sari, MS, Iasha, \& Kalengkongan, 2020). Komik juga akan membuat siswa SD Islam senang belajar karena menyukai komik (Nisak, Arifin, \& Fahyuni, Eni Fariyatul Rahmawati, 2021).

Jika dilihat dari sudut pandang positif, membaca komik dapat membantu mengembangkan imajinasi anak, komik dapat memberikan model yang dapat digunakan untuk membentuk kepribadian siswa (Murti, 2020). Membaca komik dapat membantu memvisualisasikan imajinasi anak yang belum bisa membaca. Visualisasi siswa SD Islam diperlukan karena imajinasi mereka masih minim (Amelia, 2018). Buku ajar fikih berformat komik yang inovatif ini diharapkan dapat mempermudah proses pembelajaran dan meningkatkan hasil belajar siswa SD Islam (Umiyati, 2021). Oleh karena itu, penelitian ini bertujuan untuk mengembangkan buku teks fikih berformat komik untuk meningkatkan hasil belajar siswa SD Islam. Komik adalah media artistik yang menggunakan serangkaian gambar statis dalam urutan tetap, teks tertulis sering. Buku teks berbasis komik (Acosta et al., 2002). Saat ini mendukung gagasan bahwa kata-kata dan gambar bekerja sama dengan baik untuk memberikan informasi pembelajaran. Komponen komik visual dari buku teks fikih berformat merupakan bagian dari daya tarik siswa dan dapat memberikan mekanisme untuk meningkatkan siswa sekolah dasar (Nisak et al., 2021). Saat teks dan gambar digabungkan, kinerja dan retensi membaca ditingkatkan dibandingkan dengan teks tanpa ilustrasi (Rohmanurmeta \&\& Dewi, 2018). Menggabungkan informasi visual dengan penjelasan verbal dapat menyebabkan pemecahan masalah yang lebih kreatif bagi beberapa siswa (Tatalovic, 2018). Komik telah digunakan untuk mempromosikan keaksaraan siswa dan telah terbukti mengarah pada bacaan lain dan sebagian besar pendidik setuju bahwa membaca adalah prediktor utama keberhasilan akademis (Aka, 2019). Dalam beberapa kursus sastra, komik tampaknya membantu siswa sekolah menengah menjalin ikatan yang lebih substansial dengan karakter (Dasar, 2021). Dengan menyusun materi pendidikan dengan cerita, komik dapat menggunakan narasi situasional untuk memberikan konteks materi dan dengan demikian mekanisme untuk meningkatkan pembelajaran siswa (Abe et al., 2020).

Buku teks fikih berformat komik yang dikembangkan dalam penelitian ini terdiri dari sampul, pendahuluan, isi, dan sampul (Umiyati, 2021). Pemilihan alur cerita dari komik dibuat, mengambil tema 
kehidupan sehari-hari sehingga siswa dapat lebih membayangkan kondisi yang terjadi. Materi fiqih yang dipelajari dalam komik ini adalah materi bersuci di kelas 1 pada kompetensi dasar mengenal tata cara bersuci.

\section{METODE PENELITIAN}

Penelitian ini menggunakan model Research and Development (R\&D) Dick and Carey untuk mengembangkan buku teks fikih berformat komik (Rahmadi, 2019). Langkah-langkah pengembangan model Dick and Carey yang digunakan meliputi analisis, perancangan, pengembangan, implementasi, dan evaluasi yang dijelaskan pada Gambar 1. Sedangkan yang menjadi peserta penelitian ini adalah siswanya kelas 1 SD dengan 22 siswa.

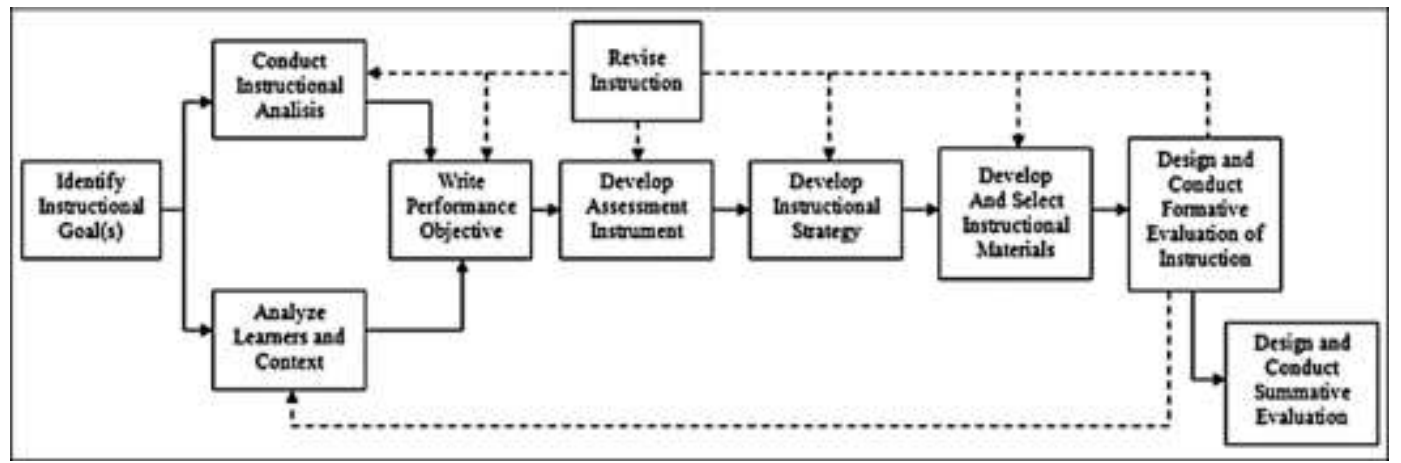

Gambar 1: Alur Pengembangan Dick dan Carey

Instrumen yang digunakan dalam penelitian ini adalah lembar validasi ahli dan tes hasil belajar materi purifikasi. Validasi yang diperlukan dalam penelitian ini terdiri dari 3 validator yaitu ahli media, ahli materi, dan ahli bahasa. Data yang diperoleh dari hasil instrumen penilaian materi aqidah, penilaian komponen media, penilaian bahasa dalam media dianalisis secara deskriptif dengan menggunakan perhitungan skala penilaian. Batasan keunggulan produk buku teks aqidah berformat komik berdasarkan kriteria interpretasi skala penilaian berkisar antara 0-100\%. Pada lembar tes hasil belajar siswa terdiri dari pemahaman materi dengan ilustrasi gambar,gambar animasi, kejelasan peristiwa dalam gambar, latihan ilustrasi peristiwa, dan kejelasan teks bacaan dalam buku teks fikih berformat komik. Instrumen tes hasil belajar siswa telah diuji validitasnya dengan korelasi product moment pearson yang menunjukkan nilai sebesar 0,0777 yang menunjukkan bahwa tes tersebut tergolong instrumen valid. Selain itu, pengujian ini diuji reliabilitasnya dengan cronbach alpha dengan nilai 0,0688 yang menunjukkan bahwa tes tersebut tergolong reliabel sehingga dapat digunakan.

Teknik analisis data menggunakan statistik deskriptif dan statistik inferensial. Statistik deskriptif digunakan pada lembar validasi media.(Arikunto, 2020) Sedangkan untuk menentukan tingkat validitas media pembelajaran yang dikembangkan digunakan kriteria penilaian kualifikasi sesuai dengan Tabel 1 .

Tabel 1: Kriteria Validitas

\begin{tabular}{lcl}
\hline Kategori & Tingkat Validitas & Persentase (\%) \\
\hline Layak/tidak perlu revisi & Sah & $76-100$ \\
\hline (Arikunto, 2020)Cukup layak/revisi sebagian & Cukup Valid & $51-75$ \\
\hline Kurang layak/revisi sebagian & Kurang Valid & $26-50$ \\
\hline Tidak layak/revisi total & Tidak sah & $<26$ \\
\hline
\end{tabular}

Analisis statistik inferensial menggunakan uji-t berpasangan korelasi product-moment dengan kriteria jika nilai p-nilai statistik uji-t adalah 0,00 yang berarti $(<0,05)$. Dapat disimpulkan bahwa Ho ditolak dan Ha diterima. 


\section{HASIL DAN PEMBAHASAN}

1. Guru dan Peneliti

Kesiapan dari guru dan peneliti juga menjadi faktor yang mendukung keberhasilan media pembelajaran buku teks fikih berformat komik. Selain menyiapkan instrumen dalam kegiatan pembelajaran, guru hendaknya menguasai materi yang akan disampaikan dan menguasai serta memimpin kelas. Ketika ada siswa yang masih cenderung pasif dalam kegiatan pembelajaran, guru harus segera meminta siswa untuk bertanya, menjawab pertanyaan, atau membantu menjelaskan kepada siswa lain. Selain itu, pengajar juga melakukan pendekatan individual kepada siswa. Hal ini membuat siswa merasa nyaman dalam proses belajarnya. Memurnikan materi cukup mudah sehingga siswa tidak membutuhkan waktu yang cukup lama untuk berdiskusi atau bertanya tentang materi ini. Namun peneliti kesulitan menentukan hari yang tepat untuk melakukan penelitian yaitu penerapan uji coba lapangan, karena jadwal sekolah untuk pengajaran Fiqih saat minggu sudah usai. Maka untuk mengatasi hal tersebut peneliti, pengajar, dan pihak sekolah sebaiknya mengubah jadwal mata pelajaran Fiqih yang dilaksanakan keesokan harinya agar peneliti dapat segera mengambil datanya. Perhatian guru terbagi antara mengontrol kondisi kelas untuk berdiskusi secara tertib dan memberikan penjelasan di depan kelas, yang menyebabkan banyak siswa yang menyambar dan menyibukkan diri di dalam kelas. Karena itu,pengembangan buku teks fiqih berformat komik untuk sd islam.

2. Hasil

a. Hasil Penilaian untuk Ahli Konten dan Desain

Pratinjau isi buku teks fikih berformat komik yang telah diterjemahkan ke dalam bahasa Inggris ditunjukkan pada Gambar 2.

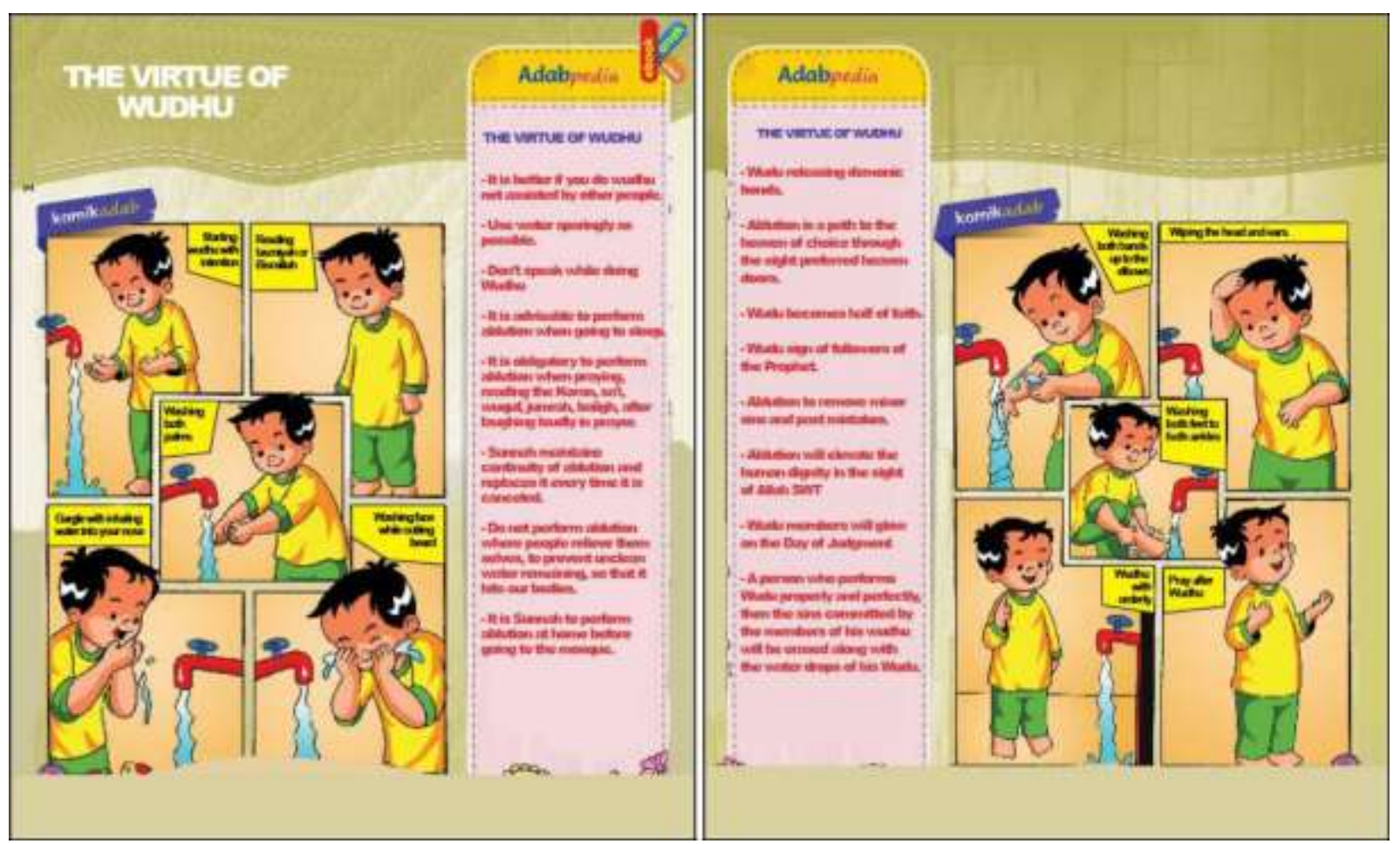

Gambar 2: Pratinjau isi Buku Ajar Fiqih Berformat Komik

(Sumber: Pratinjau Hasil Pengembangan yang diadaptasi oleh Arifin dkk. (2019))

Data penilaian uji ahli isi dilakukan dengan instrumen angket (Lihat Tabel 2) dan hasil rancangan pakar menggunakan instrumen angket (Lihat Tabel 3). 
DOI : https://doi.org/10.31004/basicedu.v5i6.1570

Tabel 2: Hasil Tes untuk Ahli Konten

\begin{tabular}{|c|c|c|c|}
\hline \multirow[b]{2}{*}{ Tidak } & \multirow[b]{2}{*}{ Kriteria } & \multicolumn{2}{|c|}{ Penilaian } \\
\hline & & 1 & ke-2 \\
\hline 1 & Kesesuaian cover media komik dengan materi fiqh & 82 & 94 \\
\hline 2 & Kejayaan judul media komik & 88 & 98 \\
\hline 3 & Petunjuk penggunaan media komik yang mudah & 86 & 98 \\
\hline 4 & dipahami Kejelasan tujuan media komik & 85 & 94 \\
\hline 5 & Kejelasan karakter dalam media komik & 84 & 98 \\
\hline 6 & Kejelasan urutan kejadian dalam gambar & 85 & 95 \\
\hline 7 & Kesesuaian media komik dengan materi sakral & 88 & 98 \\
\hline 8 & Kesesuaian materi dengan standar kurikulum Kalimat & 86 & 96 \\
\hline 9 & yang digunakan dalam penyajian teks balon Kesesuaian & 86 & 98 \\
\hline 1 & & & \\
\hline 0 & materi yang dikemas dalam media komik & 81 & 92 \\
\hline
\end{tabular}

\section{b. Percobaan}

Uji coba kelompok besar melibatkan 22 siswa kelas I. Prosedur uji coba kelompok besar mengikuti rencana pelaksanaan pembelajaran yang telah dibuat oleh peneliti. Berdasarkan hasil angket yang diberikan kepada siswa, mereka setuju bahwa buku teks fikih berformat komik ini memudahkan mereka dalam memahami materi dengan ilustrasi gambar, gambar animasi pada media komik, kejelasan peristiwa dalam gambar pada media komik, latihan ilustrasi peristiwa dalam komik, dan kejelasan teks bacaan dalam media komik, yang ditunjukkan dari persentase masing-masing kriteria tersebut adalah $100 \%$.

Sedangkan kriteria lain menunjukkan bahwa materi dapat dipahami dengan mudah dan dapat meningkatkan hasil belajar, dapat dilihat sebagai berikut: 1) judul media komik (21 siswa menjawab ya dan 1 menjawab tidak), dengan persentase 95,5\%. 2). Bentuk huruf yang digunakan pada sampul media komik (19 siswa menjawabnya dan 3 siswa menjawab tidak), dengan persentase 86,5\%.3). Bentuk huruf yang digunakan dalam media komik (20 siswa menjawab ya dan 2 siswa menjawab tidak), dengan persentase 91\%. 4) Penyajian cerita dalam media komik (21 siswa menjawab ya dan 1 siswa menjawab tidak), dengan persentase $95,5 \%$.

Pengembangan Buku Teks Fiqih Berformat Komik Untuk SD Islam

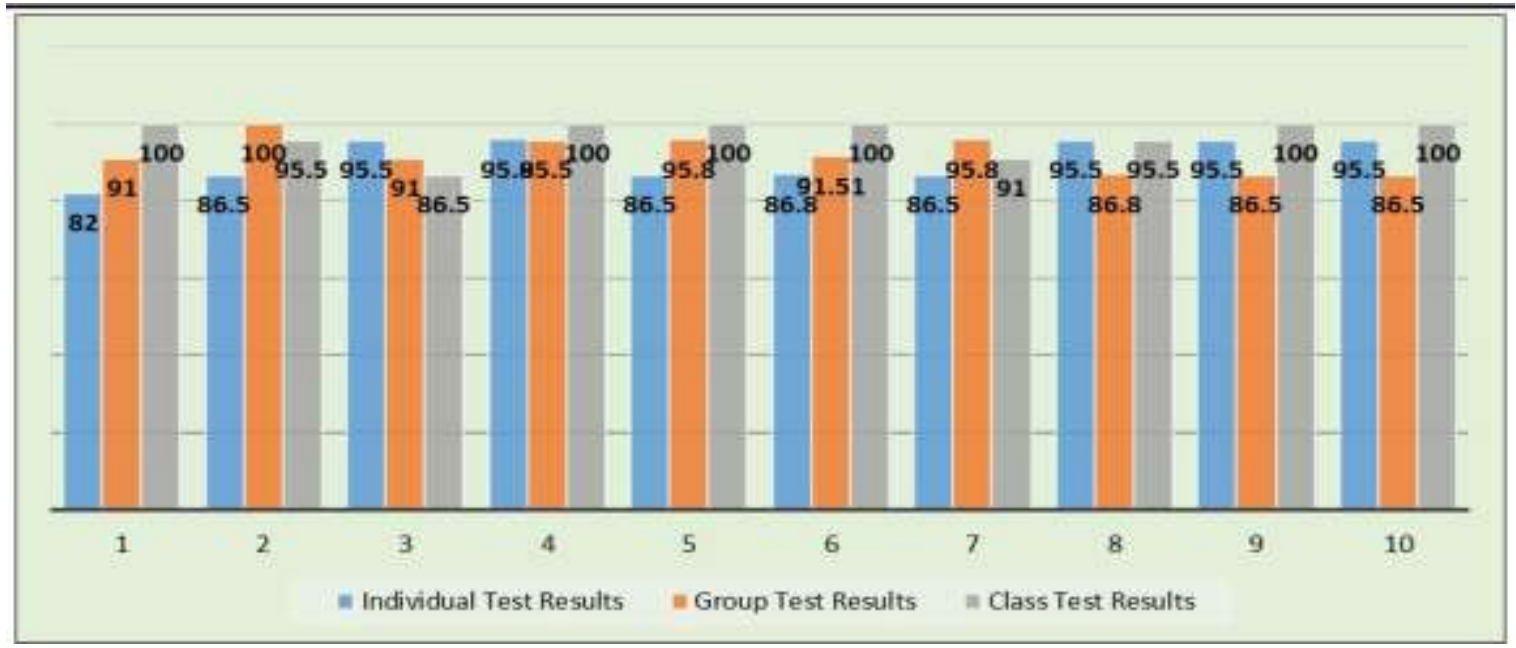

Gambar 3: Hasil Tes Belajar Siswa 
c. Hasil Uji Kelayakan, Uji T, Pretest, dan Post test

Tabel 4: Hasil Uji t Korelasi Sampel Berpasangan

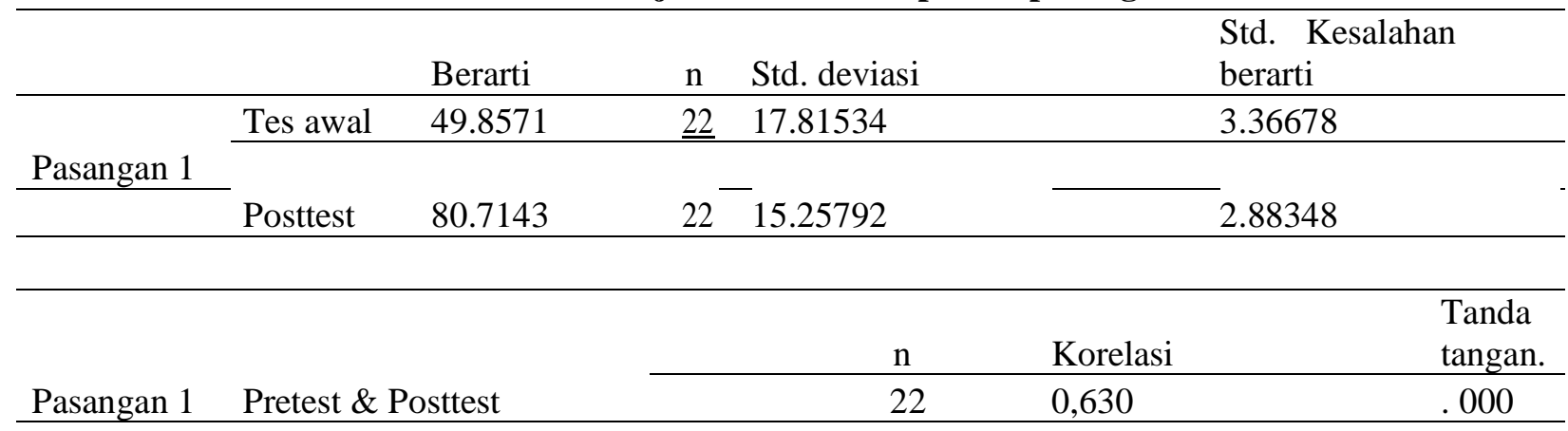

Berdasarkan rerata atau nilai rata-rata pada tabel di atas, maka selisih hasil belajar pretest dan post test yaitu hasil pretest menunjukkan nilai rata-rata 49,85, dan hasil post test menunjukkan rata-rata nilai 80,71 . Karena nilai $\mathrm{p}$ value statistik uji t adalah 0,00 yang berarti $(<0,05)$, maka dapat disimpulkan bahwa Ho ditolak dan Ha diterima. Artinya terdapat pengaruh yang signifikan terhadap rata-rata skor pretest dan post-test. Data ini juga menunjukkan bahwa terdapat peningkatan yang signifikan rata-rata hasil belajar siswa setelah mendapat perlakuan baru yaitu penerapan buku teks fikih berformat komik ini.

d. Uji Efektivitas

Tabel 5: Hasil Statistik Deskriptif

\begin{tabular}{llll}
\hline Statistik deskriptif & \multicolumn{2}{c}{ Std. Deviasi } & $\mathrm{n}$ \\
\hline Tes awal & \multicolumn{1}{c}{ Berarti } & \multicolumn{2}{c}{. } \\
\hline Posttest & 9.6429 & .55872 & 22 \\
\hline
\end{tabular}

Tabel di atas menunjukkan nilai rata-rata dan standar deviasi hasil belajar post test (variabel terikat) dan buku teks model buku komik anak (Variabel independen). Nilai rata-rata hasil belajar post test adalah 80,71, dengan standar deviasi 15,25 . Nilai rata-rata buku teks fikih untuk buku teks fikih berformat komik yang diterapkan peneliti adalah 9,64 dengan standar deviasi 0,55.

\section{Tabel 6: Hasil R Square}

Ringkasan Model

\begin{tabular}{|l|l|l|l|c|c}
\hline Model & R & R Square & Disesuaikan & Std. Kesalahan dari & \\
\hline & & & R Square & Memperkirakan & \\
\hline 1 & $.227 \mathrm{~A}$ & .051 & .015 & 15.14435 & \\
\hline
\end{tabular}

A. Buku teks fiqh berformat komik prediktor (konstan)

$\mathrm{R}=0,227$ besarnya koefisien. Hubungan antara buku teks fikih berformat komik siswa (variabel bebas) dengan hasil belajar siswa post test (variabel terikat). $\mathrm{R}$ Square sebesar 0,051 berarti $5,1 \%$, hal ini menunjukkan bahwa perubahan hasil belajar siswa ditentukan oleh buku teks fikih berformat komik sebesar $5,1 \%$ sedangkan peningkatan hasil belajar siswa sebesar 94,9\% ditentukan oleh variabel lain di luar variabel dalam penelitian ini. Terhadap hasil belajar siswa kelas I mata pelajaran aqidah.

Implementasi buku teks fikih berformat komik mengandung berbagai faktor yang mendukung keberhasilan implementasi. Lingkungan belajar berpengaruh signifikan terhadap buku teks fikih berformat komik (Mamaghani et al., 2018). Karena kondisi ruang kelas yang cukup luas dengan ventilasi yang memadai 
membuat siswa betah belajar di dalam kelas, sehingga siswa akan fokus untuk mengikuti kegiatan pembelajaran yang dilakukan.

Kondisi siswa kelas 1 SD Rabannisangat heterogen. Ada siswa yang tergolong cerdas dan ada juga siswa yang tergolong kurang cerdas. Ada siswa yang aktif, dan ada siswa yang pasif. Selain itu, mayoritas siswa SD Islam berasal dari TK yang berbeda dengan latar belakang yang berbeda pula. Kondisi siswa sangat membantu keberhasilan penerapan pembelajaran dengan menggunakan buku ajar fiqih berformat komik, dimana siswa yang baru menginjak bangku sekolah dasar lebih senang dengan media pembelajaran bergambar (Hosler \& Boomer, 2020), agar lebih mudah dipahami. Karena pemilihan alur cerita dari komik dibuat, buku teks fiqih berformat komik memiliki pengaruh yang signifikan terhadap keberhasilan penelitian ini. Karena memiliki cerita yang tidak membosankan juga diangkat dari fenomena yang sedang terjadi. Penggunaan buku teks fikih berformat komik juga membantu siswa agar tidak bosan dengan membaca buku yang hanya berisi beberapa tekssaja.

\section{KESIMPULAN}

Berdasarkan proses penelitian dan pengembangan buku teks aqidah berformat komik, dapat dikemukakan kesimpulan bahwa implementasi buku fikih berformat komik. Buku ajar, didesain semenarik mungkin sehingga sangat sesuai dengan karakter siswa pada usia 7 tahun khususnya kelas I Madrasah Ibtidaiyah atau setingkat Sekolah Dasar. Dalam buku teks fikih berformat komik berisi permasalahan terkait dalam kehidupan sehari-hari, sehingga siswa SD Islam dapat melakukan apa yang telah mereka baca diterapkan dalam kehidupan sehari-hari. Tingkat kelayakan buku teks fikih berformat komik ini dapat dikatakan layak karena hasil uji coba produk dapat membuktikan hal tersebut. Hasil validasi dari ahli isi menyatakan bahwa materi dalam buku teks aqidah berformat komik ini valid atau layak digunakan. Hasil validasi ahli desain diperoleh bahwa desain buku teks aqidah berformat komik tersebut valid atau layak digunakan. Tingkat efektivitas buku teks aqidah berformat komik ini terdapat pengaruh yang signifikan dari penerapan buku teks pada buku komik anak. Dengan demikian, buku teks aqidah berformat komik untuk kelas dapat dikatakan memiliki kualitas yang baik. Hal ini dikarenakan buku teks aqidah berformat komik dapat membantu meningkatkan hasil belajar dan daya tarik belajar, sehingga membantu siswa dalam belajar dan meningkatkan hasil belajar siswa SD Islam.

\section{DAFTAR PUSTAKA}

Abe, F., Albrow, M., Amidei, D., Anway-Wiese, C., Apollinari, G., Atac, M., ... Zucchelli, S. (2020). Measurement Of The Cross Section For Production Of Two Isolated Prompt Photons In P $\bar{p}$ Collisions At S =1.8 Tev. Physical Review Letters, 70(15), 2232-2236. Https://Doi.Org/10.1103/Physrevlett.70.2232

Acosta, D., Affolder, T., Akimoto, H., Albrow, M. G., Ambrose, D., Amidei, D., ... Zucchelli, S. (2002). Limits On Extra Dimensions And New Particle Production In The Exclusive Photon And Missing Energy Signature In [Formula Presented] Collisions At [Formula Presented]. Physical Review Letters, 89(28), 1-7. Https://Doi.Org/10.1103/Physrevlett.89.281801

Aka, K. A. (2019). Integration Borg \& Gall (1983) And Lee \& Owen (2004) Models As An Alternative Model Of Design-Based Research Of Interactive Multimedia In Elementary School. Journal Of Physics: Conference Series, 1318(1). Https://Doi.Org/10.1088/1742-6596/1318/1/012022

Amelia, D. J. (2018). Pengembangan Bahan Ajar Cetak Dalam Bentuk Komik Untuk Siswa Kelas Iii Sekolah Dasar. (Jp2sd) Jurnal Pemikiran Dan Pengembangan Sekolah Dasar, 6(2), 136. Https://Doi.Org/10.22219/Jp2sd.V6i2.7152

Ananda, R. (2014). Analisis Implementasi Pendekatan Saintifik Dalam Pembelajaran Pendidikan 
5042 Pengembangan Modul Pembelajaran terhadap Hasil Belajar Mata Pelajaran Aqidah di Sekolah Dasar - Jumiati Siska, Muhammad Kristiawan

DOI : https://doi.org/10.31004/basicedu.v5i6.1570

Kewarganegaraan: Studi Kasus Di Kelas Iv Sd Islam Ibnu Sina Kabupaten Bandung Dan Kelas Iii Sd Laboratorium Upi Cibiru. Universitas Pendidikan Indonesia.

Ananda, R. (2017). Peningkatan Hasil Belajar Siswa Pada Materi Operasi Pengurangan Bilangan Cacah Dengan Menggunakan Blok Dienes Siswa Kelas I Sdn 016 Bangkinang Kota. Jurnal Cendekia: Jurnal Pendidikan Matematika, 1(1), 11.

Arikunto, S. (2020). Prosedur Penelitian.

Dasar, S. (2021). Fandi Agustiandi Umbaran, 2021 Pengembangan Media Pembelajaran Meme/Rage Comic Dalam Pembelajaran Ips Sekolah Dasar Universitas Pendidikan Indonesia | Repository.Upi.Edu | Perpustakaan.Upi.Edu.

Heglund, H. F. (2016). Kunsthøgskolen I Oslo , Avdeling Balletthøgskolen Loererutdanning Utdanning: Eksamenstype: Emnekode: Praktisk-Pedagogisk Utdanning Skriftlig Hjemmeeksamen Ppdpe / Ppdfd I Pptpe / Pptfd Pedagogikk Og Fagdidaktikk Kandidatnummer : Dato For Innlevering :

Hosler, J., \& Boomer, K. B. (2020). Are Comic Books An Effectiveway To Engage Nonmajors In Learning And Appreciating Science? Cbe Life Sciences Education, 10(3), 309-317. Https://Doi.Org/10.1187/Cbe.10-07-0090

Lestari, N., Wulansari, F., \& Khasanah, M. (2021). Pengembangan Diri Anak Sd Berbasis Seni Pada Masa Pandemi Di Kupang. 3(1), 33-44. Https://Doi.Org/10.23917/Bkkndik.V3i1.14666

Murti, S. Dan Heryanto. (2020). Jurnal Ilmiah Wahana Pendidikan. Jurnal Ilmiah Wahana Pendidikan Https://Jurnal.Unibrah.Ac.Id/Index.Php/Jiwp, 6(3), 295-307. Https://Doi.Org/10.5281/Zenodo.3737983

Nisak, N. M., Arifin, M. B. U., \& Fahyuni, Eni Fariyatul Rahmawati, I. M. (2021). The Development Of Comic Formatted Fiqh Textbool For Islamic Elementary School. European Journal Of Education Studies, Vol. 8, Pp. 114-125.

Nita Nur Qoriah, S. I. R. W. A. (2017). Upaya Meningkatan Keterampilan Menulis Narasi Melalui Media Komik Dalam Pembelajaran Bahasa Indonesia Pada Siswa Sekolah Dasar. Didaktika Dwija Indria, 5(6).

Rahmadi, I. F. (2019). Technological Pedagogical Content Knowledge (Tpack): Kerangka Pengetahuan Guru Abad 21. Jurnal Pendidikan Kewarganegaraan, 6(1), 65-74. Https://Doi.Org/10.32493/Jpkn.V6i1.Y2019.P65-74

Restian, A., \& Sari, E. K. (2019). Pengembangan Media "Comic Life” Untuk Gerakan Literasi Siswa Kelas Iii Di Sekolah Dasar. Jurnal Pendidikan Dasar Nusantara, 5(1), 159. Https://Doi.Org/10.29407/Jpdn.V5i1.13187

Rofifah, D. (2020). 済無no Title No Title No Title. Paper Knowledge. Toward A Media History Of Documents, 12-26.

Rohmanurmeta, F. M., \&\& Dewi, C. (2018). Pengaruh Media Komik Digital Pelestarian Lingkungan Terhadap Prestasi Belajar Tematik Pada Siswa Sekolah Dasar. Prosiding Snasppm, 3(1), 87-90.

Sari, Y., Ms, Z., Iasha, V., \& Kalengkongan, J. (2020). Peningkatan Kemampuan Berpikir Kritis Melalui Model Auditory, Intellektualy, Repatition (Air) Berbantuan Komik Ipa Di Sekolah Dasar. Refleksi Edukatika : Jurnal Ilmiah Kependidikan, 11(1), 121-126. Https://Doi.Org/10.24176/Re.V11i1.5045

Tatalovic, M. (2018). Are Comic Books An Effectiveway To Engage Nonmajors In Learning And Appreciating Science? Journal of Science Communication, 17(1), 1-7. Https://Doi.Org/10.22323/2.17010501 